\title{
Voluntary Control of Desire
}

\author{
Thomas W. Smythe \\ North Carolina Central University, Durham, NC, USA \\ Email: thomaswsmythe@yahoo.com
}

Received 16 October 2015; accepted 19 February 2016; published 22 February 2016

Copyright (C) 2016 by author and Scientific Research Publishing Inc.

This work is licensed under the Creative Commons Attribution International License (CC BY).

http://creativecommons.org/licenses/by/4.0/

(c) (i) Open Access

\begin{abstract}
In this paper, I will investigate whether there is any way in which our desires or wants are under our voluntary control. I shall argue that even if our desires are not under our voluntary control, there are still significantly many cases in which we can properly be blamed, praised, or upbraided for having certain desires.
\end{abstract}

\section{Keywords}

\section{Desire, Voluntary, Praise, Blame}

\section{Introduction}

Desires and beliefs have figured prominently in the explanation of human action for philosophers. Some philosophers think that desires and beliefs combine to cause our actions. It is, therefore, appropriate to inquire whether we properly can be held responsible, blamed, praised, reproached, and the like for having the desires and beliefs we have. William P. Alston has argued that our beliefs are not under our voluntary control, and that we are ill advised to praise or blame people for having the beliefs they have. Alston suggests that similar considerations hold for the other propositional attitudes (Alston, 1988). In this paper I will investigate whether there is any way in which our desires or wants are under our voluntary control. I shall argue that even if our desires are not under our voluntary control, there are still sufficiently many cases in which we properly can be blamed, reproached, or upbraided for having certain desires. I rely on the reader to be sympathetic in filling out these cases, since it is not indisputable whether these locutions involve praise or blame.

Let me begin by pointing out that there are many locutions that encourage us to think of desires as subject to praise. We say "She wants to help the needy", "He wants to be a doctor", "She is so warm and friendly", and "He would never be dishonest". We often seem to blame people for their desires: "He wants to hurt her", and "How could you like him?” We often suggest the voluntary control of desires "Make up your mind; do you want to go out to eat or not?" "I finally decided I want to be a computer programmer", and "I can't help wanting to smoke; I have no choice" (the suggestion being that in other cases one does have a choice). People frequently 
speak of someone's being in a situation in which they have to decide whether or not to want something. All these locutions and many more imply that we frequently have the capacity to effectively decide or choose what we are to desire. Some philosophers have held that even though many of our desires are involuntary, there are a great many desires which are under our voluntary control. These desires are ones that we properly can be held responsible for. For example, Peter Smith and O. R. Jones argue that many, or perhaps even most, of the desires or pro-attitudes involved in the explanation of human action are in some measure "up to us"... To revert to our earlier examples: it surely is to some extent up to Jack whether he wants to look like everyone else at the partywe can sensibly ask whether he ought to feel like that, we may perhaps hold him accountable for still succumbing to the temptation to feel that way, and so on. And Jill's desire for a laboratory sample, which is likely to be the result of some deliberative process, is even more clearly something for which it could make sense to hold her accountable (for example, we can ask whether she has deliberated carelessly or well). Even in the case where Jill succumbs to the fancy for a second helping of cheesecake, there is the question whether her contrary desires should not have been more firmly held. In all these cases, then, the complex of desires which lie behind an action is itself, by and large, something for which the agent can be held to account (Smith and Jones, 1986).

More recently, Philip Pettit and Michael Smith have argued that people believe what they ought to believe and desire what they ought to desire. Pettit and Smith use conversation to show that people can have rationally chosen desires. This seems to me to be palpably false. I shall argue that most of the desires we form are not of our own choosing. I shall begin by asking how we should think of this capacity to form desires we ought to have (Pettit and Smith, 1996).

It is natural to think of this capacity on the model of choosing or deciding to desire via the maximally direct control we have over the motions of our body parts and limbs, the voluntary movements of which constitute "basic actions", actions we perform "at will", just by the intention, volition, choice, or decision to do so, things we "just do" without doing something else voluntarily. Let us call this kind of control we have over actions we typically bring about by basic actions, following Alston, "basic voluntary control." (Alston, 1988). If we do have voluntary control of our desires, we have the same sort of reason for supposing it to be basic control that we have for supposing ourselves to have basic control over the movements of our body parts, viz., that we are often hard pressed to specify any voluntary action by the doing of which we get our body to move.

Before proceeding a preliminary point is needed. Our issue does not concern free will or freedom of action, at least not in the sense in which that goes beyond one's action being under the control of the will. In this paper I shall only be concerned with the issue of whether desires are under voluntary control. Thus unconscious desires are ruled out by their very nature.

\section{Basic Voluntary Control}

Let us now turn to a critical examination of the basic control thesis, the thesis that one can take up at will whatever desire one chooses. I shall maintain that we are so built that we are not able to take up desires at will. By saying we are "so built" that we cannot form desires at will I intend to put forward an empirical thesis or psychological fact about human beings in general. I am not making a conceptual point about the very concepts of desire and belief, although I am sympathetic to such theses that have been advanced in the literature on belief at will (Williams, 1971; O’Shaughnessy, 1973; Scott-Kukures, 1993). I shall first consider the case of belief, and show a parallel consideration for wanting. The argument, if you can call it that, consists simply in asking you to consider whether you have any such abilities. Consider the following case. Suppose you are a philosopher who is applying for a job in philosophy at academic Siberia. You get to know the chairman of the department to which you are applying and you learn that he is fanatically committed to the belief that the soul is distinct from the body and lives forever, often undergoing reincarnation. You want the job badly, but you are a confirmed materialist. You notice that in philosophical discussions with the chairman he becomes very angry and upset at the mere mention of materialism or naturalism. You have every reason to believe that if he finds out you are a materialist he will not hire you. Can you force yourself to embrace dualism, the immortality of the soul, and reincarnation even if you want to, and are willing to sacrifice your integrity to get the job? Could you do what it takes to get the job? Remember we are speaking of believing at will. It seems clear to me that I have no such power. Volitions, decisions, and choosing don't hook up with anything in the way of propositional attitude inauguration, just as they don't hook up with the secretion of gastric juices. I very much doubt that any human beings are endowed with the power of taking up beliefs at will. If I were to set out to bring myself into a state of 
belief in reincarnation, just by an act of will, I might assert that p with an expression of conviction, or dwell favorably on the idea that p, and the like. All this I can do at will, but none of this amounts to taking on the belief in reincarnation. That is all show, an elaborate pretense in believing. Having gone through all this, my doxastic attitudes will remain just as they were before. We have just as little control over beliefs formed by perception, introspection, memory, and simple uncontroversial inferences. Our beliefs are products of our environments and our past and current psychological histories. This is not just a generalization about human beings from my own case, but what seems to me to be true by reflection on the powers and abilities of human beings in general.

It might be pointed out that the foregoing example only shows that some beliefs are not voluntary, such as strongly held beliefs. To make a case for saying beliefs are not under our basic voluntary control it helps to have a wide range of examples. Let us consider a belief that is not one we would be likely to be firmly committed to. Suppose I hear a weather report that says it is ninety percent probable that it will rain tomorrow. I form the tentative belief that it will rain tomorrow. Can I will not to believe it will rain tomorrow, just like that? It may seem that I can, but only because I can do certain things, such as watch for a later weather report, think about how the weather report has been inaccurate in the past, and the like. What seems obvious to me is that I cannot just decide not to pay attention to the weather report and will to form the belief that it will not rain tomorrow. I will argue that a similar point holds for desires.

Let us now turn to desires. Are desires ever under our direct basic voluntary control? Can we desire that $\mathrm{p}$ at will? I shall consider first what are called by many people the appetitive desires or physical drives for food, drink, sleep, and sex. People can have a desire to watch a ballet. But there is no physical drive to watch a ballet. If someone goes a long time without eating, however, they become hungry. Try if you will, by a direct effort of will, to not desire to sleep when you are sleepy. You can alter your desire to sleep by taking a stimulant such as caffeine. But you cannot eliminate the desire to sleep by a mere act of will. You can think about doing something enjoyable with your time; dwell favorably on a book you would like to read, and the like, but you will not be able to alter your desire to sleep without taking some kind of action. A thirteen year old boy who sees sexually explicit scenes on TV cannot help wanting to have sex. He cannot alter his desire the way he can raise his arm, by a mere act of will. His desire is not under his voluntary control. One way to extinguish a desire is to satisfy it. If I desire a chocolate milkshake, I can eliminate the desire by drinking a chocolate milkshake. However, even if I can satisfy a desire willingly or unwillingly it by no means follows that I eliminate or form the desire at will, or that I have basic voluntary control over such desire formation. It would have to be true that I have effective voluntary control over whether I have a desire to drink a chocolate milkshake when I think about drinking a chocolate milkshake and it seems a good thing to do., all other things considered. Thus it seems that our appetites, cravings, yearnings, longings, and urges cannot be formed by direct act of will and are not under our direct voluntary control the way our control over our bodily parts is under our basic voluntary control. Thirst, for instance, is caused by a lack of water. It causes drinking to be particularly enjoyable and can only be eliminated by drinking something, not by willing it to go away.

The discussion to this point has been carried out in terms of appetitive desires. But there are plentiful cases of desire that are not appetitive desires. I often want to change the oil in my car. I am glad that I have a can of oil, or else wish that I had one. I never have an appetite for a can of oil, and never hunger or yearn for one, although I could if I were a collector of oil cans. I have never had an urge for a can of oil. A can of oil is neither appealing nor unappealing. We often want to eat, for social or nutritional reasons, when we are not at all hungry, and when we view the prospect of eating without pleasure. Finally, imagine that I was given the choice between being electrocuted or being shot. I say that "I desire to be electrocuted rather than shot". It is clear that I do not view the prospect of being electrocuted as enjoyable. There are desires that we are forced to form in practical situations where the object of desire is not appealing or viewed with pleasure. Often we must act one way rather than another and we are forced to form, and act on, some desire. I may be deciding on whether to go on a picnic tomorrow. I must either plan the picnic today or not, and it would be unwise to ignore the matter, thereby acting on the desire not to go on the picnic tomorrow. Hence the better part of wisdom is to form some desire, as best I can.

I will suggest that in such cases the situation is best viewed in some way other than as initiating a desire at will. The suggestion is that in these cases of desire although the supporting considerations are seen as less conclusive, here too the desire follows automatically, without intervention by an act of will, from the way things seem at the moment to the subject. In the case of appetitive desires the desire is formed by bodily changes that lead to it, deprivation of food, or whatever. In the case of our other desires, like our desire for a can of oil, desire 
is still determined by what plays a similar role, in the sense that one alternative is more likely than another, or what leads to that. Suppose it seems equally likely that it will rain or not rain tomorrow. If that were really the case, and it seldom is, could I desire to plan for the picnic tomorrow just by choosing to do so? Here it seems I would be in a pickle. I could arbitrarily make a choice, as we often do in a grocery store between two or more cans of soup that look equally satisfactory. But desire formation is another matter. How could I simply choose to desire one can of soup rather than another when they seem equally satisfactory? To do so would be to form a desire in the face of the lack of any significant reason to do so. It seems clear to me that we cannot do this.

There may be cases where a person can will a desire to go away. Suppose an obese person becomes hungry while watching a TV commercial that shows some delicious looking food. The obese person may be able to focus on the desire for food and make to go away by concentrating on their pathological propensity to eat too much. This might be a case of extinguishing a desire at will. However, this would require a sequence of mental steps, and would not be a basic action.

\section{Non-Basic Immediate Voluntary Control}

The demise of basic voluntary control is not the end of the view that we have voluntary control over our propositional attitudes. One can hold that desires are subject to what Alston calls "indirect voluntary control". (Alston, 1988) But I want to discuss what Alston calls "immediate voluntary control." (Alston, 1988). It is called "immediate" because the agent can carry out her intention "right away", in one uninterrupted intentional act without having to return to the attempt a number of times after having been occupied with other matters. Alston uses the term "direct control" for both basic and immediate voluntary control. Consider the famous example of turning on the light. In turning on a light I must perform one or more bodily movements and these movements must have certain consequences, causal or conventional, in order for me to be said to have performed the non-basic action in question. In order for it to be true that I turn on a light I must flip the switch with my finger or some other part of my body, and this must result in the light turning on. Actions like this are not done as an immediate consequent of a volition and so are not strictly done "at will". Nevertheless I might be blamed for my failure to turn on the light when I was supposed to do so. It is clear that if desires are under our immediate voluntary control that suffices to render them susceptible to praise or blame as well as ascriptions of responsibility.

I will not rehash the discussion of basic voluntary control or Alston's subsequent discussion for beliefs in terms of desires. Instead I shall proceed by giving some examples of cases where we can create a desire in a way that is analogous to flipping a switch in order to turn on a light. Consider the famous example of creating an appetitive desire, the electrical stimulation of pleasure centers in the brain. Such stimulation will give the subject a desire to continue the stimulation. If I want to create in myself a desire to continue the stimulation of the pleasure centers in my brain, all I have to do is hook up with the required apparatus. But one might consider this to be an exceptional case. I cannot usually do anything like this in order to bring about a desire in me. But one can imagine there being more examples of this.

Suppose that with more knowledge of the brain more desires could be produced. Then we could produce or extinguish desires in our brains in ways analogous to flipping a switch, and the thesis that desires are not under our voluntary control would be considerably weakened. We can say that under the current dispensation desires do not seem to be formed at will, or by doing something like flipping a switch. But currently, we can also use hypnosis to produce or extinguish desires.

Robert Audi has made a useful threefold distinction that is relevant to my discussion. He distinguishes between generative responsibility, retentive responsibility, and prospective responsibility (Audi, 1993). I shall briefly consider how our desires are caused and assert that for each of these different kinds of causes of desire we do not have generative responsibility for their formation. We do not generally have generative responsibility for our desires. Desires are most naturally caused by bodily changes or physiological conditions. Desires for food, drink, sleep and sex are triggered by bodily changes. It seems clear that we have no voluntary control over whether we form such a desire, or whether they come into existence.

Belief also causes desire. If I believe that crack will satisfy a certain hankering I will automatically desire crack. I may desire to appear on television because I believe that if I appear on television I will be liked by others. It seems we have little control over the causes and origins of such desires. However, you can deliberate about whether to form a desire for crack, or any other appetitive desire. You can deliberate about whether to form a desire as a means to something else you want, such as a desire to take crack in order to feel high. It may 
be that we can exercise control over the psychological causes of our desires, but not the bodily or physiological causes of desires.

Desires can cause other desires. I may desire to desire something. I may desire to desire to do some writing which in turn causes me to desire to do some writing, In this case I can have control over my desire to write since it is up to me whether I want to write or not.

Robert Audi makes a good point about the control of the genesis of our desires. He says we have no interest in trying to control the origin of our desires because we can normally exercise control over whether our desires and beliefs will issue in the relevant actions (Audi, 1993). However, I think that this is an overstatement. We often do not want to have certain desires and beliefs. For example, most mature and responsible people will not want beliefs and desires that are racist or Chauvanist in character.

Next consider retentive responsibility. I can exercise some control over whether my desires are retained for a long period of time, or over whether they are strengthened or weakened. If I desire to smoke a pipe, I may desire not to smoke the pipe, and take action by ceasing to smoke. My action can result in diminishing my desire to smoke a pipe. \# In fact, it seems I can suppress a desire at will. If I want some candy, I can remove the desire by thinking about something else and ignoring the desire until it goes away. Of course, this is not a basic action, since it requires a sequence of mental steps.

If one surveys the literature in the science of psychology on self-control it becomes evident that there is little or nothing written on the control of desire generation or formation. Most of the literature I have found is focused on the control of behavior that issues from our desires, or the ability to strengthen or weaken a desire. This supports Audi's belief that there is little point in trying to control the genesis of our desires and beliefs.

\section{Speed of Desire Formation}

Another factor which militates against the voluntary control of desire formation is the speed at which they are formed. For many people, a desire or want is often formed almost instantly upon encountering an object. We see something we like and we want it straight off. Often it may just strike someone that they have a desire for something, for example when they are shopping. It is a mark of maturity to exercise self-control over desire formation and not to want everything we encounter that is attractive.

This is not to say that all desires are quickly formed. Although desires are often formed quickly, they can also be cultivated. Students may have to cultivate a taste for beer. Beer does not taste good to everyone on the first try. Many young people want beer because of social reasons. They develop a desire for beer over a long stretch of time. Someone may not have a desire to read Shakespeare until they force themselves to do so.

Those desires that are formed with the most speed are usually mandatory. Desires that are closer to perception are more mandatory, and those desires associated with planning are more purposive and can be formed voluntarily. In fact, the speed of desire forming processes derives in part from their manditoriness: the fact that there is no need to decide whether to form a given desire eliminates planning time. Such speed in desire formation no doubt has an evolutionary advantage. Desire formation is quick because this is optimal for reacting to situations in one's environment.

\section{Blameworthy Desires}

I now want to consider whether we are ever blameworthy for our desires, even though they may arise involuntarily. I begin by considering what can be called "putting oneself in the relevant position". Consider the married man who desires to go to bars where he believes there will be some women he can meet and pick up. He desires to go to the bar and he knows that if he goes there, he will no doubt form the desire to converse with any good looking females he meets there, and form other attendant desires as well. We can blame him for going to the bar, but we may also want to blame him for desiring to go to the bar. We can say that at least he should have exercised self-control and not gone to the bar. Can we blame him for desiring to pick up a woman at the bar? He knew that he would in all likelihood form this kind of desire for some female in the bar, and that once he formed the desire he would act on it. In this case it seems we can hold the man responsible both for his decision to go to the bar and his later desire to pick up a particular female conspecific because he was putting himself in a position where he know he would form a desire to pick up a female, and knew he would succumb to the desire if given the opportunity. If he had exercised self-control he wouldn't have put himself in a position where he would have formed the desires in question. Another example of this kind is someone who is on a diet and goes 
into a certain restaurant where she knows full well that she will be tempted to form desires for a variety of fattening desserts. In both cases I am assuming that $\mathrm{P}$ can exercise self-control and is not compelled to fall into these situations. This is simply the old fashioned precept of avoiding temptation.

Consider an analogous case for beliefs. There are situations in which we can choose whether or not to put ourselves in a context where we will be subjected to certain belief forming processes that we can be praised or blamed for having. One example is the housewife and the salesman. Suppose my Aunt is extremely suggestible to salesmen who come to her door selling their wares. She knows full well that if she lets the salesman in her house to give his sales pitch he will probably make her believe she needs new pots and pans, a vacuum cleaner, and the like. Knowing that she will buy things she doesn't really need she lets the salesman in anyway. It seems we can blame her for putting herself in a position where she will form the belief that she needs the pots and pans. We blame her for having that belief because she knew from past experience that she would succumb and form the belief in question.

In these examples, which can be easily multiplied, we have immediate voluntary control over whether to put ourselves in situations where we will form desires and beliefs that we can be blamed for forming. We are responsible for our desires and beliefs thus formed because we knew that by performing certain actions we would form those desires and beliefs that lead to further actions which we ought not to be doing. But these cases may not constitute the majority of cases in which we form desires and beliefs. In the majority of humdrum cases of desire and belief formation we may not have immediate voluntary control over their formation.

The question whether someone can be blamed for their desires can be approached more directly. Consider the following. Suppose someone comes to believe that women are inferior, in some important way, to men. Suppose he goes on to conclude that women should not be allowed to vote, hold jobs, or go into politics. Further reflection leads him to the view that all men can treat women as sexual objects as they so desire. Finally, he concludes that forcing women to do as you wish them to do so they serve any desire a man may have is desirable. You might call this the Mike Tyson syndrome.

Now many of us will agree that such a person is culpable and guilty. But wherein does the guilt consist? Suppose that in persisting in his views about women, and in satisfying his desires with respect to them, he loses his job and is eventually incarcerated for rape. His guilt does not consist solely in his taking the actions he takes; at least part of the guilt lies in his perverse desires and beliefs about women. Even if he had not acted on his desires and beliefs, would he not have been guilty nonetheless? I think he would have been. We do in fact sometimes think that a person is guilty by virtue of the desires and beliefs they have. Thinking so is rationally justified if we are to be, in any degree, responsible for what kind of person we are to become. As this example illustrates, conventional locutions sometimes indicate that we are blameworthy for our desires.

A well-known problem arises here. If we blame someone for having a certain belief or desire, does this not imply that they ought not to believe or desire what they do? And if one ought not to desire a certain thing, does that not imply that they can control their desire in some way? This is a version of the "ought implies can" thesis. Presumably the thesis does not require that we be able to turn off our desires directly. Perhaps this means that when we have a desire that cannot be checked with a "second-order desire", as Harry G. Frankfurt calls them, we ought not to blame the person for such a first-order desire (Frankfurt, 1971).

There are means of controlling desires available. We can use hypnosis, aversive stimuli, and behavior modification techniques. Perhaps even by habitual action one can create desires, as when people force themselves to exercise or run. All of this is indirect control. But it seems clear that there are desires we ought to have, and desires we ought not to have. If someone has a child, they ought to want to bring it up and give it a good start in life. Someone ought not to want to see people bleed for the pleasure of it. It seems that we can alter our desires indirectly and that we ought to do so in certain circumstances. We seem to think that people have some control over their beliefs and desires and we praise or blame them on moral grounds, even though we can only control our beliefs and desires indirectly.

\section{References}

Alston, W. P. (1988). The Deontological Conception of Epistemic Justification. In J. Tomberlin (Ed.), Philosophical Perspectives, Epistemology. Atoscadero, CA: Ridgview Publishing Company. http://dx.doi.org/10.2307/2214077

Audi, R. (1993). Responsible Action and Virtuous Character. Action, Intention, and Reason. Ithaca, NY: Cornell University Press.

Frankfurt, H. G. (1971). Freedom of the Will and the Concept of a Person. Journal of Philosophy, 68, 5-20. 
http://dx.doi.org/10.2307/2024717

O’Shaughnessy, B. (1973). The Will: A Dual Aspect Theory. Cambridge: Cambridge University Press.

Pettit, P., \& Smith, M. (1996). Freedom in Belief and Desire. Journal of Philosophy, 93, 429-449. http://dx.doi.org/10.2307/2940892

Scott-Kukures, D. (1993). On Belief and the Capacity of the Will. Philosophy and Phenomenological Research, LII. Williams, B. (1971). Deciding to Believe. Problem of the Self. Cambridge: Cambridge University Press. 